\title{
HARMONIC ANALYSIS OF COMPOSITE PROPELLER FOR MARINE APPLICATIONS
}

\author{
Y. Seetharama Rao ${ }^{1}$, B. Sridhar Reddy ${ }^{2}$ \\ ${ }^{1,2}$ Dept of Mechanical Engineering, G.V.P College Of Engineering, Visakhapatanam-48, Andhra pradesh, India \\ yseetharamarao24@gvpce.ac.in
}

\begin{abstract}
Present work proposes a harmonic analysis to design a propeller with a metal composite material to analyze its displacements and natural frequencies using Ansys software. In order to evaluate the effectiveness of composite over metals, harmonic analysis is performed on both composite and metal propellers using Ansys. Proposed method shows substantial improvements in composite propeller over the metal propellers. From the results of harmonic analysis, it was found that composite propeller is safe against resonance phenomenon. In this paper effort is made to reduce frequency of the composite propeller so that advantage of weight reduction can be obtained. The comparison analysis of metallic and composite propeller has been made for the maximum displacements and the response graphs for the displacements and frequency were plotted.
\end{abstract}

Keywords: Composite Propeller, Natural frequency, Harmonic analysis, FEA

\section{INTRODUCTION:}

Composite materials are used in numerous structural applications. The application of composite materials technology to marine architecture has increased with particular benefits of its light weight ,less noise and pressure fluctuation and less fuel consumption. A structural analysis of the propeller blade is difficult because its geometry and loading is complex. The classical curved beam, plate and shell theories were applied in early structural analysis of propellers. These approaches have been demonstrated to be successful, but special assumptions limit their application of the methods. The finite element method is so popular and has been used by many researchers.

Traditionally marine propellers are made off manganese-nickelaluminium-bronze and nickel aluminium bronze for their superior corrosion resistance, high yield strength, reliability and affordability. However, it is expensive to machine metallic materials into complex material geometries. Moreover, metallic propellers are subjected to corrosion and cavitation damage, fatigue induced cracking, and have relatively poor acoustic damping properties that can lead to noise due to structural vibration.

\section{LITERATURE REVIEW:}

The application of composite materials technology to marine architecture has increased with particular benefits of its light weight, less noise and pressure fluctuation and less fuel consumption[1].The finite element method is so popular and has been used by many researchers[2].The technology advances and the costs of composites are becoming cheaper[3].Moreover composites can offer the potential benefits of reduced corrosion and cavitation damage, improved fatigue performance, lower noise, improved material damping properties and reduced life time maintenance costs[4]. Changes to the tensile and flexure properties of marine-grade glass -reinforced polyster, vinylster and resole phenolic composites after exposure to radiant heat are investigated[5].When using the Genetic Algorithm approach, some techniques for parameter setting to provide quick and correct results were discussed along with the influence of these parameters[6].The numerical results are in aggrement with experimental data and the general characteristics of the propeller flow seem to be quite well predicted[7].A strong correlation was identified between the divergence ship speed and the change in the tip pitch angle of the blades in brief communication static divergence of self twisting composite rotors. The methodology used is equally applicable to other structures such as tidal and wind turbines[8].Taylor[9] considered a propeller blade as a cantilever rigid at the boss. Chang Suplee[10] investigated the main sources of propeller blade failure and resolved the problems related to blades symmetrically. G.H.M.Beek[11] examined the interference between the stress conditions in the propeller blade and the hub. Gau Fenglin[12] carried out stress calculations for fibre reinforced composite thrust blade.

\section{MODELING OF PROPELLER:}

Modeling of the propeller has been done by using CATIA V5R17. In order to model the blade, it is necessary to have sections of the propeller at various radii. These sections are drawn and rotated through their respective pitch angles. Then all rotated sections are projected on to right circular cylinders of respective radii. Finally the propeller is modeled by using 
four noded quadrilateral shell element and is converted into a solid model.

\subsection{Mesh Generation Using Hyper Mesh:}

The solid model is imported to Hyper mesh 10.0 and hexahedral mesh is generated for the same. The composite propeller meshed model is shown in Fig.1.2D mesh is generated by splitting the areas and then converted into 3D mesh using the tool linear solid. The number of elements created is 27388 and number of nodes created is 52412. Now the pressures are applied on the propeller which is obtained from FLUENT 6.3. Then the meshed model is imported into the ANSYS. Solid 45 element is selected for aluminum metal and solid 46 element type is selected for composite propeller.

Table1. Material Properties

\begin{tabular}{|c|c|}
\hline$S_{2}$ Glass fabric/Epoxy & Aluminium \\
\hline $\mathrm{E}_{\mathrm{x}}=22.925 \mathrm{Gpa}$ & Young's modulus $\mathrm{E}=70000 \mathrm{MPa}$ \\
\hline $\mathrm{E}_{\mathrm{y}}=22.925 \mathrm{Gpa}$ & Poisson's ratio NUXY $=0.34$ \\
\hline $\mathrm{E}_{\mathrm{z}}=12.4 \mathrm{Gpa}$ & Mass density $=2700 \mathrm{~kg} / \mathrm{m}^{3}$ \\
\hline $\mathrm{NUXY}=0.12$ & Damping co-efficient $=\mathbf{0 . 0 3}$ \\
\hline NUYZ $=0.2$ & \\
\hline NUZX $=0.2$ & \\
\hline $\mathrm{G}_{\mathrm{xy}}=4.7 \mathrm{Gpa}$ & \\
\hline $\mathrm{G}_{\mathrm{yz}}=\mathrm{G}_{\mathrm{zx}}=4.2 \mathrm{Gpa}$ & \\
\hline$\rho=1.8 \mathrm{gm} / \mathrm{cc}$ & \\
\hline
\end{tabular}

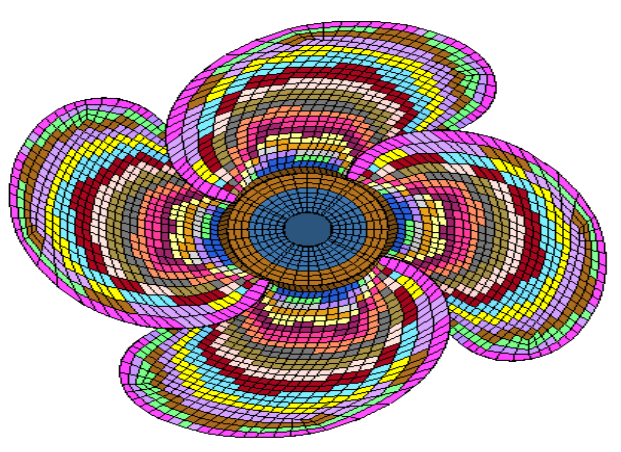

Fig.1 Composite propeller meshed model

\subsection{Boundary Conditions And Loads:}

The propeller is fixed in all directions at hub and shaft intersection. The pressure is applied to the propeller which is obtained from the FLUENT 6.3. The boundary conditions are shown in Fig. 2

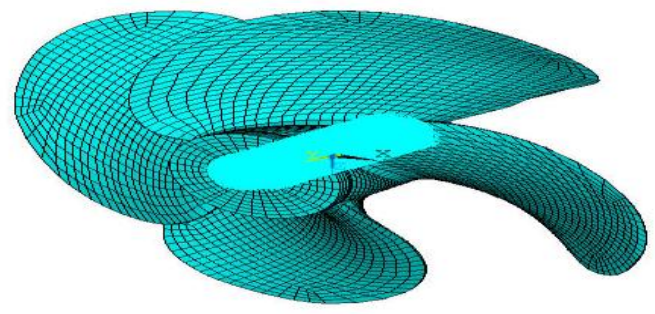

Fig.2 Propeller FE model in ANSYS boundary conditions

\section{HARMONIC ANALYSIS:}

This analysis gives the ability to predict the sustained dynamic behaviour of structures, thus it enabling to verify the designs will successfully overcome resonance, fatigue and other harmful effects of forced vibrations. Harmonic response analysis is a technique used to determine the steady state response of a linear structure to loads that vary sinesoidally with time. It calculates the propellers response at several frequencies and obtain the graphs of displacement versus frequencies.

\section{RESULTS AND DISCUSSIONS:}

\subsection{Harmonic analysis of Aluminum Propeller:}

From the harmonic analysis, the displacements of various nodes and stresses for different elements over the entire frequency range 0 to $3000 \mathrm{~Hz}$ with amplitude were obtained. The natural frequencies of the propeller lies in the same above frequency range. The observed peaks in the frequency response graphs were plotted. Fig 3, Fig 4 and Fig 5 shows the variation of displacement in $\mathrm{X}, \mathrm{Y}$ and $\mathrm{Z}$ directions with frequency at node 1428. The maximum displacement of component of $X, Y$ and $Z$ directions obtained in harmonic analysis for aluminium propeller due to the pressures from CFD are shown in Table No. 2.

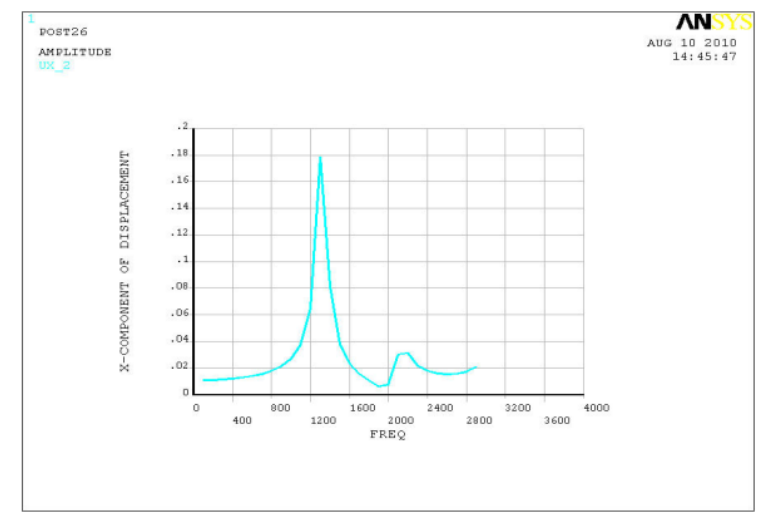

Fig 3. X-Component of Displacement versus Frequency response graph of Aluminum Propeller 


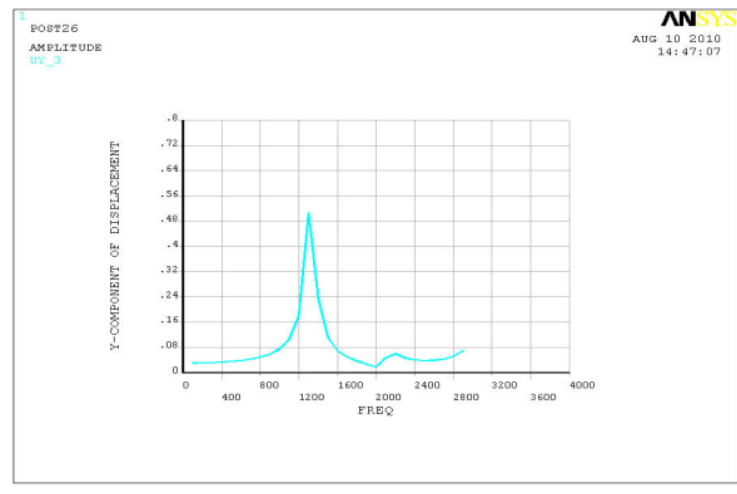

Fig 4. Y-Component of Displacement versus Frequency response graph of Aluminum Propeller

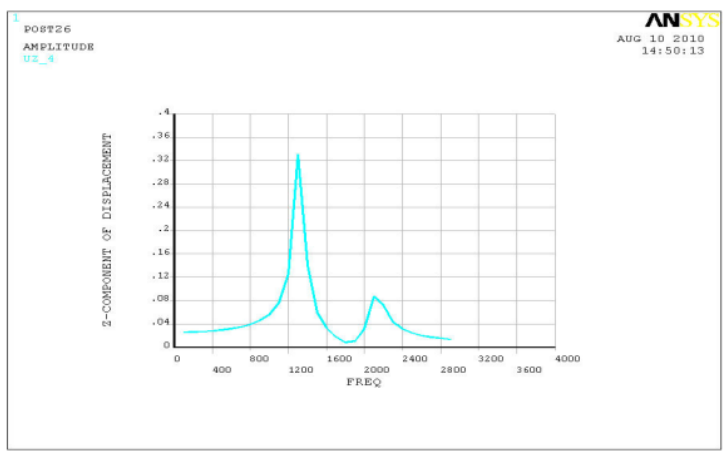

Fig 5. Z-Component of Displacement versus Frequency response graph of Aluminum Propeller

Table2. Maximum Displacements of Aluminium Propeller

\begin{tabular}{|c|c|}
\hline $\begin{array}{c}\text { Displacements of } \\
\text { Aluminium Propeller }\end{array}$ & Maximum \\
\hline X-Component & 0.1784 \\
\hline Y-Component & 0.5025 \\
\hline Z-Component & 0.3250 \\
\hline
\end{tabular}

\subsection{Harmonic Analysis Of Composite Propeller:}

The natural frequencies of the propeller lie in the frequency range of 0 to $2000 \mathrm{~Hz}$. The observed peak in the frequency response graphs was plotted. Fig 6, Fig 7 and Fig 8 shows the variation displacement in $\mathrm{X}, \mathrm{Y}$ and $\mathrm{Z}$ directions with frequency at node 1428 .

The maximum displacement of component of $\mathrm{X}, \mathrm{Y}$ and $\mathrm{Z}$ directions obtained in harmonic analysis for Composite propeller due to the pressures from CFD are shown in table no 3.

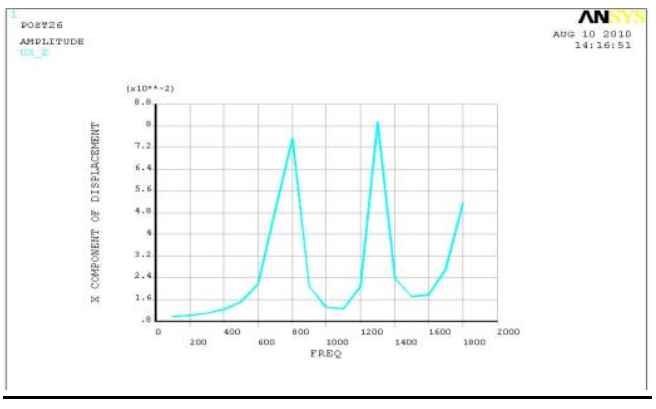

Fig 6.X-Component of Displacement versus Frequency response graph of Composite Propeller

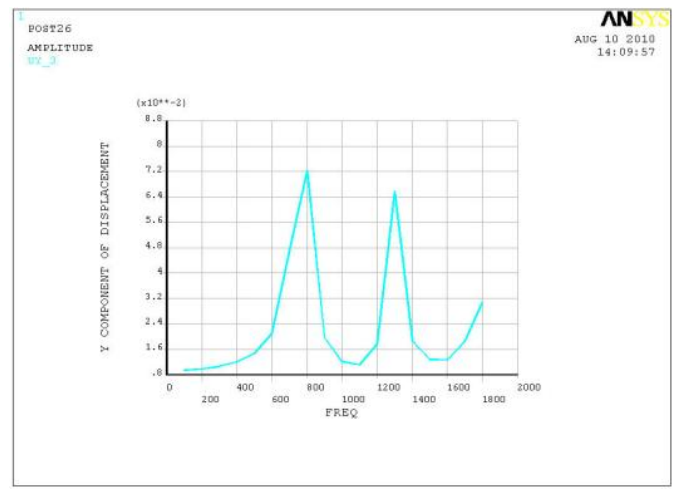

Fig 7.Y-Component of Displacement versus Frequency response graph of Composite Propeller

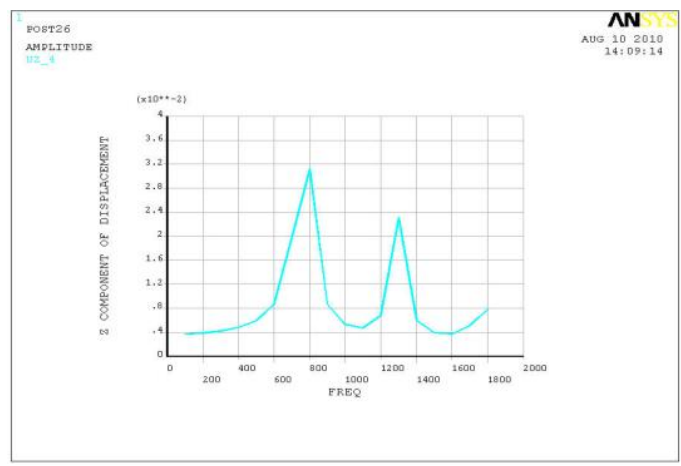

Fig8. Z-Component of Displacement versus Frequency response graph of Composite Propeller

Table3. Maximum Displacements of Composite Propeller

\begin{tabular}{|c|c|}
\hline $\begin{array}{c}\text { Displacements of } \\
\text { Composite Propeller }\end{array}$ & Maximum \\
\hline X-Component & $0.08192 \mathrm{~mm}$ \\
\hline Y-Component & $0.0723 \mathrm{~mm}$ \\
\hline Z-Component & $0.02925 \mathrm{~mm}$ \\
\hline
\end{tabular}




\section{CONCLUSIONS}

1. From the results of harmonic analysis, composite propeller is safe against resonance phenomena.

2. From the results of harmonic analysis, damping effect is more in composite propeller which controls the vibration levels.

3. Harmonic analysis is carried out on both aluminium and composite propellers, it was observed maximum displacement for composite propeller is less than the aluminium propeller.

4. The weight of the composite propeller is $42 \%$ less than the aluminium propeller.

5. This study helps in predicting the operating frequency of the propeller.

\section{REFERENCES:}

[1] J.F.Tsai, H.J.L.a., Analysis of Underwater Free Vibrations of a Composite Propeller Blade. Journal of Reinforced Plastics And Composites, 2008. Vol. 27, No. 5: p. 447-458.

[2] H.J.Lin , W.M.L.a.Y.M.K., effect of stacking sequence om nonlinear hydroelastic behavior composite propeller Journal of Mechanics, 2010. Vol. 26, No. 3: p. 293-298.

[3] Toshio Yamatogi, H.M., Kiyoshi Uzawa,Kazuro Kageya, Study on Cavitation Erosion of Composite Materials for Marine Propeller. 2010.

[4] Young, Y.L., Fluid-structure interaction analysis of flexible composite marine propellers. Journal of Fluids and Structures, 2008. 24(6): p.799-818.

[5] A.P. Mouritz, Z.M, Post fibre mechanical properties of marine polymer composites, Elseveir science Ltd,2000,47:p.643-653.

[6] Chang j.h, Y.S. Shih, Basic design of series propeller with vibration consideration by genetic algorithm, Journal of Marine Science and Technology,2007.12(3),119-129.

[7] Amoraripei M, Predection of marine propeller performance using RANS, Numerical analysis and Applied Mathematics, International Conference, 2008,771-774.

[8] Liu Z,Y L Young, Static divergence of self twisting composite rotors, journal of fluids and structures, 2010,26(5),841-847.

[9] Taylor,D.W, "The speed and power of ships", Washington, 1933.

[10] Chang-sup lee, yong-jik kim,gun-do kim and in-sik nho. "Case Study on the Structural Failure of Marine Propeller Blades" Aeronautical Journal, Jan 1972, pp8798

[11] G.H.M.Beek, visitor, Lips B.V., Drunen. "Hub-Blade Interaction In Propeller Strength", the society of naval architects and marine engineers, May 24-25, 1978, pp 19-1-19-14.

[12] Gau-Feng Lin "Three Dimensional Stress Analysis of a Fiber Reinforced Composite Thruster Blade", the society 